\title{
Non-Stop Mega-Fun Learning
}

\author{
Victor Selman, American University
}

Ruth Corey Selman, Representative to the United Nations

Jerry Selman, Q- ERA, Inc.

Elsie Selman, Speech Consultant

Fun is a basic genetic instruction for all higher animals because it is the way they learn. Humans must learn all their lives and therefore continue to play and look for fun well into old age.

---Wm. Glasser, M.D. (Control Theory)

\begin{abstract}
Learning how to learn can be reinforced in many ways. But learning without play or fun is difficult---grim and boring. Classical Pedagogy with its "serious" student-teacher-administrative rituals may be the major failing of our educational system.

Unorthodox ways currently used in colleges to augment persuasion and articulation ability of business school students is to use "stand-up" comedy (University of Chicago), song-writing, storytelling and bare improvisation (Vanderbilt University-Owens Management); and for a Shakespearean motivational spin, relative to other management skills at the corporate executive level (Northrup-Grumman).

Another novel learning way is by continual repetition through audio-visual media, where information is presented in a risk-/stress-free environment. Suggestion, Auto-suggestion. and Suggestology have been used for years in Europe; for example, at Moscow University three years of studying French are compressed into less than one year by total immersion of students into a close network of students-parents-teachers-environment-activities---where, for example, only French is spoken.
\end{abstract}

Other approaches are to have abstract ideas in the sciences translated into physical learning devices such as toys or robots: repetition with/without background music-operas or Mozart --, using the olfactory stimulation of aromatherapy, "pigging out" on pizzas before, or during, the learning session, or encouraging the ingestion of chocolate "stuff" to enhance retention.

\section{Introduction}

Can the trademarked plastic building blocks from Lego determine strong college candidates? Can the blocks replace SAT scores or grades? Can it identify leadership, conflict negotiation and effective communication skills? Corporate communities nationwide have discovered the blocks as a means to identify characteristics necessary for top employees, says LEGO executive Michael Seabury. [See.www.lego.com] At Harley-Davidson and Toyota, all new employees use LEGO blocks to sharpen their problem-solving skills. At Florida Atlantic University (FAU), Boca Raton, budding electrical engineers design LEGO Robots for robot races in Professor Daniel Raviv's inventive problem-solving class.

We are uni-lingual in a multilingual Babel culture, without translators, with continually- changing rules of grammar---a new "Esperanto" language without an unabridged dictionary for the many ambiguous, core meanings embedded within our multi-cultural educational heritage. An intriguing aspect about mega-fun learning in the 21 st Century is that we just do not have the time nor the capability nor the comic instincts to face the grim, unsolvable problems we inherited, which we must try to resolve today and tomorrow---to teach us something about ourselves and each other, and give everyone a laughing start to real unstressful learning. When we are both learning and 
having fun, long hours and hard work is tolerable---without fun, these tasks become drudgery. "Fun is such an integral part of our lives that most of us could not conceive of life without it," Glasser posits [7], "yet it can be as much in conflict with the other needs as they are with each other. It can be in conflict with survival, with belonging, with power. But when you have power, you also have more time for fun, so power can also be very supportive of this need. I believe that fun is the basic genetic instruction for all higher animals because it is the way they learn. Humans driven by complex, psychological needs that are always in some conflict must learn all their lives and therefore continue to play and look for fun well into old age. In fact, losing interest in looking for fun may be a sign of mental deterioration in older people."

American education, both as a learning system and a philosophy of learning-- is in a state of great controversy, as we enter Millennia-3. Seen as archaic, medieval, Wave-2 hold-outs by many futurists and change agents, little institutional reform is being made by the establishment to enter the digital "Wave-3" world of accelerated Super-Learning. What most corporations want to see in their new-MBA hires is "someone who is articulate, persuasive and can read a balance sheet---in that order." Business schools have consistently turned out graduates who could read financial statements and do cabalistic statistical analysis---but that's all. Having college students become "Jerry Seinfeld's" for a day gives them valuable communication skills and increased confidence. If my students can handle a "stand-up" comedy routine, they can handle anything [11].

At the University of Chicago, Director/Actor Bret Scott of the Second City acting troupe was assigned to coach graduate business students to improvise comedy routines. And earlier this year at Vanderbilt University in Nashville, TN, a business student stood before his classmates and delivered a five-minute stand-up routine "laced with self-deprecating humor.

The executives of Northrop Grumman's Electronic Sensors and Systems Sector are studying the strategy of war and competition through Shakespeare's plays. A company called Movers and Shakespeare offers leadership training and impromptu costumed play-acting in "drive-by Shakespeare" retreats. "You can talk about the 12 great qualities of leadership and two hours later the students will not remember what was on the list. You've got to draw people into a story, and I'm convinced that's what they will remember and not the principles," concluded Professor Useem, Wharton School, Center for Leadership and Change

Simultaneously, there is much interest in promising new alternatives and innovations in education, exhibiting possibilities for new curricula and new instructional patterns---as well as a sharp break with traditional forms of educational pedagogical programming, even to "trick" students to think for themselves, and to perform serious inquiry into the various disciplines [10]. But, unfortunately, there is no quick-fix for the agenda of educational reform ---to learn better, faster and become a self-motivated, articulate person, with a passion to help others---and save the world!

Consider the intensity of concentration that youngsters exhibit with those small hand-held computer games! Are they toys? How do we define play in the digital world? Elementary schools are now supplying students with original \$100 Sony PlayStations, including joysticks and educational CDs of free video games that "sneak" in lessons in a way those street-smart kids can appreciate [12]. Professor Gordon Berry (UCLA) says that the new PlayStation Program is part of a national trend--- instead of competing with TV and video games for the attention of their students; schools are using them to capture it. A California-based software company called Lightspan, which has Berry as their adviser, provides math, reading and writing lessons cleverly formatted into games--like Goggle Math--that allow students to work at their own pace, extending the class-room into their homes, and involving their siblings and grandparents[5].

The use of mechanical learning aids and simulation techniques have been explored by educators at various levels: Escalante (Garfield High School) uses a wind-up walking-shoes toy for a step-by-step approach to algebra, and a plastic monkey climbing up and down a small pole to illustrate the inverse function--exchanging $\underline{y}$ for $\underline{x}$; Dr. David Carson (Rensselaer Polytechnic Institute) creates a level playing field for science and humanity majors using Tinkertoy blocks for his courses in technical writing and editing; Marva Collins (Chicago Westside Preparatory School) uses a number of original learning aids; Deirdre Donovan (Transit Tech, NY) uses visual play — cartoons, 
art prints, movie clips-to win "Special Education" converts to Shakespeare [11]; Dr. Victor Selman (The American University) uses a multiplicity of original and modified-by-him high-tech toys and robotic models to reinforce management concepts and Operations Research applications---enhanced with bi-weekly pizza pre-sessions for their de-stressing qualities. [See Appendix B, Selman MEDICASA Model] Maria Galvez-Martin (Ohio State at Lima) focuses on the importance of teaching Social Studies with toys through play [5], as a hands-on approach for in-service teachers with role playing and journal recording in the course "Teaching with Toys." "Every-body loves toys. Some of us just pretend that we are too grown-up for them, but the truth is that most adults are just closeted children," says Yael Li-Ron in "Ready for the Future" in the 30 October 2000 issue of Newsweek magazine [10].

If we define play as fun, and learning as play, we can include most of the electronic and computerized games that so fascinate today's children. Because of their connection with problem-solving skills, Mega-Fun may come under the "Montessori" heading of learning how to learn. The new Wave-3 Quantum_paradigm for education, integrates all connected, relevant subjects under the umbrella of how, when and what we learn. In this emerging unifying paradigm, the teacher is viewed from the very beginning as the communications Facilitator or "Catalyst," the guide to all the mega-sources available in our exploding world of information, communication networks and imagery---but not necessarily central to the collaborative journey with students in their quest for "street-smart" knowledge and "common-sense" wisdom. In the final analysis, "quantum" education looks to spiritual growth---the over-arching goal of inner awareness, beyond changes in subject matter or tutorial styles. Simultaneously, there are innovations for enhanced performance through self-modifications in education, exhibiting possibilities for new curricula and new instructional patterns, both horizontal and vertical---as well as a sharp break with traditional forms of pedagogical programming, even to "trick" students to think for them-selves, and to perform rigorous machine-like inquiry into the various new disciplines [8] for connecting linkages.

Some of the robotic and e-toys simultaneously involve both teachers and students in the fun and mental aspects of creative science learning. If toys are used in an inquiry manner, simplistically, and analyzed so they can be used interactively to re-discover and re-design basic scientific principles---thus enhancing new problem-solving communication skills [5]. The question is thus raised [2]:

What if it were possible to transfer information without the circuitous paths of present ways of teaching? What if a teacher could guide a student beyond the normal capacity of his/her mind by "broadcasting over the "no-fun" defensive mechanism of the normally unused $90 \%$ of the brain?

A technique that could break through that barrier in the mind that prevents us making use of the major part of our intellectual capabilities would be revolutionary.

\section{Suggestopedia et al}

The goal above is exactly what Dr. Georgi Lazanov believes he had created---a teaching method that speeds up learning 50 times, increases retention, requires virtually no effort on the part of the student, reaches retarded and brilliant students alike, and requires no special equipment. "You can lean back, relax, listen to music, and learn without effort and without realizing it. . [The senior co-author met Dr. Lazanov in New York City prior to his United Nations visit, and was impressed by Lazanov's multi-media presentation, and the need and potential of his rapid learning technique.] The possibilities of using Suggestopedia on a mass scale are very promising," At the Bulgarian Institute of Suggestology and Para-psychology, records of controlled tests reveal that hundreds of people from all levels of society learned entire two-year language courses in as little as twenty (20) days. Small experimental groups mastered courses in basic mathematics, physics, chemistry and biology in a matter of weeks! It is not hypnosis or sleep learning. It is far more practical than that. The student is fully awake and in complete control of himself, say Dr Lazanov. It is a kind of mind contact between teacher and student, based on the Yoga technique of relaxation known as Savasanna. Using suggestion and auto-suggestion, muscle tension is relaxed and the brain is relieved of the usual activities and stresses. In this relaxed free state of consciousness, or meditative state, fatigue quickly vanishes. Freed from all distractions which hamper its functioning, the brain resembles a sponge able to absorb knowledge of all kinds. "The possibilities of using Suggestopedia on a mass scale are very promising, "says Lazanov, "It is inexpensive and ideally exportable." 
The secret of this technique is that material does not reach the memory in the ordinary way, because the student does not participate consciously in the process [10]. With basic knowledge quickly and painlessly instilled, schools could increasingly become places of creative teaching and thinking. In Appendix A, Typical Classroom [French] Lesson Using Suggestology, is demonstrated against an operatic background of Brahms and Beethoven. During the time the teacher intones words against this musical back-ground, there seems to be distinct physiological changes in the body and changed brain control of alpha waves, putting a predominately rhythm of rest in the brain. Once the mind is opened in this reverie-like state, Lazanov found that the capacity to remember seems almost boundless - there is no apparent cutoff point. It is as easy to remember a hundred words than fifty [2]!

Like Dr. Lazanov, Dr. Lozano Caycedo, also a medical doctor, at the University of Madrid, investigated techniques that permit a person to modify states of consciousness and thus act on the body/mind linkage. Founding the Centre of Sophrology in 1960 in Barcelona, he initially used sophrology medically in many areas, including gastroenterology, psychiatry, and obstetrics. Caycedo says. "We teach people how to breathe properly, how to anesthetize themselves and how to relax. We reinforce in a person his capacity to take charge, and thus his capacity for hope." From medicine, Sophrology moved to sports and education, where Caycedo observed that people developed hypermesia--or super-memory - through Japanese Zen (which he considers a "perfection of Raja Yoga") and his own "dynamic relaxation" technique. Caycedo's system also used visualization exercises to achieve synchronization of body/mind rhythms, and sounds - not an orchestra like Lazanov— but by the human voice, "Left brain and right brain are stimulated globally by having the course material read almost in a singing way with special rhythms and intonation. This technique he calls terpnos $\underline{\log o s}$, and it goes back to the ancient Greeks. [Plato described it as a special tone of voice---a soft, soothing, monotonous, melodious tone somewhat like an incantation, or chant.] Sophrology teachers are even given voice coaching, along the training lines of an actor's actor or lead singer [3]."

Like Lazanov's Suggestology, Caycedo's Sophrology brings not only learning, but therapeutic spin-off benefits---improved self-confidence, improved creativity, improved emotional development and self-expression, and freedom of limited ideas about capabilities. What powers, what talents will surge into being as more of the mind is freed?

\section{Summary}

In the West, UNESCO and the Ford Foundation had expressed interest in the Lazanov approach, and the New York State Medical College had invited Dr. Lazanov to speak there in 1969. Consensus at the time was very positive [6], that Lazanov's Suggestopedia was a genuine form of mind expansion. It is revolutionary--evolutionary, perhaps, but worthy of further exploration.

A "hands-on" fun workshop (with many original Robotic learning aids) will be presented by Dr. Victor Selman, including discussion/demonstration of his MEDICASA Model for developing appropriate learning aids for various business subjects---quality control, linear programming, queuing, reliability, inventory theory, simulations (Monte Carlo), work measurements, etc. Learning aids are offered as the support in learning the complex concepts inherent in the real-life environment needed to go from traditional rote learning styles to actual deep visceral learning.

Navigating Mega-Fun techniques through the Scylla and Charybdis of differing assumptions, we need to leap into bold new ideas and methods that "work" in education today. Techniques presented and those just mentioned in passing, enlighten the learning atmosphere and environment---helping to reduce the stress of mathematics and other "floating" educational anxieties. The serendipitous benefit is that both the hands-on perspective-change concept and the Suggestology transformational approach can be used in all disciplines--providing needed, rapid meta-fun-learning techniques for the high velocity 21 st Century venues ahead.

As we find ourselves in the Age of Robots, designing 'bots more humanlike, more conscious, more useful, we realize the enormity of the task that faces us. Things that kids---how to program logic and problem-solving into robots at the same time as teaching robots perceptual and intuitive things that any child can do, like running, 
sweating, listening, recognizing friendly faces---which cannot be done by even the most advanced robot today at the beginning of the millennium. The elaborate computerized problem-solving programs that researchers installed in yesterday's robots, assumed initially that the sequence of multiple high performance knowledge databases of facts, basic laws from finite-set theory, compendia of physical laws and heuristic relationships would all somehow add up to "thinking" (machine consciousness) and real world smarts. The traditional goal of understanding and replicating human intelligence has taken second place to goals shared by computer science---the development of systems to augment human abilities, without talking of "consciousness"---to focus on what we know---not how we know it. In fine, to compute common sense from multiple abstract inputs. Douglas R. Hofstadter in his 1979 work, GÖdel, Escher, Bach: An Eternal Golden Braid, talks of Artificial Intelligence (AI) as being "founded on the idea that if 'intelligence' is created on the computer, it will automatically be the same kind of cognitive consciousness that humans have. "What way(s) do children learn? How did we learn? Is learning just change? And what about Intelligence? Sherry Turkle of MIT claims that computers are heavily influencing the way people think of themselves, others and society at large [6]. Drawing on Piaget and Papert, she feels that the new generation of "microkids" is even beginning to think of themselves as machines rather than people! But learning without fun is difficult---grim and boring presentations. Humor is the secret strategic tool!

\section{References}

1. Andrews, T.G. and L.J. Cronbach, "Transfer of Training," Readings in Psychology of Learning [ed. J. Tobias] the City College, New York, 1963.

2. Bancroft, Jane, "the Lazanov Language Class," Journal of Suggestive-Accelerative Learning \& Teaching (S.A.L.T.), Vol.1, \#1, Spring, 1976.

3. _ “Caycedo's Sophrology \& Lazanov's Suggestology---Mirror Images of a system." ERIC documents on Foreign Language Teaching \& Linguistic, 1979.

4. $\quad$ Comaford, C., "Is Instructor-Led Training Dead?", PC Week, Feb.10, 1997 V14 N6 P58.

5. Flannery, Mary E., "Free Video Games Sneak in Learning," The Palm Beach Post, Palm Beach, FL, 16 October 2000.

6. Galvez-Martin, M., “Changing Teachers’ Perceptions By Helping Students Learn Social Studies with Toys Through Play,” (Ed. Hans. E. Klein,) Creative Teaching, Act 2000.

7. Glasser, Wm. Control Theory, Harper \& Row: New York, 1984.

8. Judy, R.W. \& J. B. Levine, A New Tool For Educational Administrators: Educational Efficiency Through Simulation Analysis, University Of Toronto: Canada, 1987.

9. Lazanov, G., Suggestology \& Suggestopedia, Sofia, Bulgaria, Institute of Suggestology, $1969 . \quad$ [in Bulgarian]

10. Li-Ron, Yael, "Ready for the Future?" Newsweek, 30 October 2000, pp 10-14.

11. McKenzie, M.N., "For Today’s M.B.A.s, A Serious Bit of Levity," The New York Times, Feb.23, 1997.

12. O'Brien, T., Teaching Fundamental Aspects of Science Toys, School Sciences And Mathematics, (4) pp.203-207, 1993.

13. Ostraner, S. \& Lynn Schroeder, "Misson Control Center For The Mind, "Psychic Discoveries Behind The Iron Curtain, Bantam Books (Prentice Hall): Englewood Cliffs, NJ 1970.

14. Selman, V., \& M. Luzuringa, "Use OF Learning Aids In Teaching Quantitative Courses," 1990 Teacher's Conference, The American University, Washington, DC, January 20, 1990.

15. Steinberg, Jacque, "Visual Play's The Thing: Teacher Uses Cartoons To Win Converts To Shakespeare," The New York Times, 10 May 1998.

16. Tashev, T. \& T. Nathan, "Suggestology "Bulgaria Today”, No .9, 1966. 


\section{APPENDIX A}

\section{Typical Lesson [French] Using Suggestology}

In a typical classroom at the institute [suggestology \& parapsychology], twelve people--students, housewives, laborers, professionals, old and young - relax in reclining chairs that resemble airplane seats. The room looks more like a lounge than a classroom. The lighting is subdued to enhance the calming effect. The group is listening to music, gentle soothing music. They look as if they were at a concert, completely wrapped up in the harmony of symphonic sounds. Against the background of Brahms or Beethoven, the voice of the mentor seems somewhat businesslike, or if ordering work to be done, sometimes soft and calming, then unexpectedly hard, commanding. Her voice repeats in a special rhythm, on a special scale of intonation, French word, idioms, and their translation. But the students are not really listening. They have been warned not to pay attention, not to think about whether they hear the teacher. Relax. Do not think about anything. Their conscious minds are to be totally occupied by the music.

The next day surprised students discover that even though they we sure they had learned nothing, they remember and can easily read, write and speak from 120 to 150 new words absorbed during the two-hour session.

In the same way the toughest part of the language course, the grammar rules, painlessly take root in the minds of music-lulled students. Within a month students with no prior knowledge of a language have accepted two to three thousand vocabulary words and have a good grasp of the grammar. Longitudinal tests a year later show they still know all the material learned in this incredibly effortless way [6].

Classes run four hours a day: two hours for the suggestion session, one hour for the practice and tests, one hour for new material. Students come six days a week for three months. At the end of that time they have the equivalent of a two- or three-year course, a 6,000-word vocabulary, and a complete grasp of grammar. They can read, write and speak fluently.

[Tests a year later show students retain almost all they learned in the course!]

\section{APPENDIX B}

\section{SELMAN'S M-E-D-I-C-A-S-A Model}

The MEDICASA Model is most effective for providing the necessary insights for further inventiveness, creativity and interdisciplinary usage, focusing on the development of learning aids for specific applications, and for preparing instructional goals and educational objectives [7].

O Measurement. This Quality Control Dilemma has students using micrometer calipers to measure thickness of foil-wrapped candy, and computing the Average, the Standard Deviation and the Distribution.

O Efficacy. This is the degree of higher-level integration of the unique concepts into the memory convolutions of the total brain.

O Data Development. Students plot data points for statistical control limits for samples of, say, five; and for the total expected mean and dispersion [Standard Deviation].

O Imagery \& Integration. Three-dimensional learning aids are integrated into the learning process for enhanced visualization and retention.

$\mathrm{O} \quad$ Computerization. Measured data, as well as estimated values, are fed into a graphical software package [1] for plotting statistical control limits and simulation experiments.

$\mathrm{O} \quad$ Analysis. Comparisons are made of computer outputs with hand-calculations. For clarification, students perform data evaluation, forecasts, caveats, rationales for disparities---in a dynamic format.

O $\quad$ Sensitivity. Using simulation techniques, "what if?" questions are raised regarding basics.

O Applicability. Radiational aspects of lessons learned for application to other educational venues.

Note: Abacus-type counters and Quincunx are demonstrated for concept Integration. [Colored balls simulate control limits within which the number of estimated defectives (wrappers) fall.] 